\title{
Calidad y rendimiento del carbón activado de la cáscara del fruto de calabaza (Cucurbita ficifolia) obtenido por método químico
}

\author{
Quality and performance of activated carbon from the shell of the \\ pumpkin fruit (Cucurbita ficifolia) obtained by chemical method
}

\author{
Fermín H. Arévalo ${ }^{1, \star}$ y Kevin Reátegui ${ }^{1}$
}

\begin{abstract}
Recibido: 14 junio 2019 | Aceptado: 09 mayo 2020 | Publicado en línea: 01 agosto 2020 Citación: Arévalo, FH; Reátegui, K. 2020. Calidad y rendimiento del carbón activado de la cáscara del fruto de calabaza (Cucurbita ficifolia) obtenido por método químico. Revista Forestal del Perú 35(1): 21-30. DOI: http://dx.doi.org/10.21704/rfp.v35i1.1473
\end{abstract}

\begin{abstract}
Resumen
Se obtuvo carbón activado (CA) a partir de la cáscara de la calabaza (Cucurbita ficifolia Bouchë) por activación química, usando ácido fosfórico $\left(\mathrm{H}_{3} \mathrm{PO}_{4}\right.$ al 30 y $\left.60 \%\right)$ y cloruro de zinc $\left(\mathrm{ZnCl}_{2}\right.$ al 1\%) como agentes activantes. Estos tres grupos fueron sometidos a tres distintos tiempos de activación (45, 60 y 75 minutos) para obtener nueve tratamientos. Cada tratamiento se repitió por triplicado. Se halló el rendimiento, humedad y cenizas de los nueves tratamientos. Asimismo, se evaluó la capacidad de adsorción de azul de metileno. Los resultados señalan que el agente activante influye en la capacidad de adsorción del colorante. Los carbones activados obtenidos con ácido fosfórico adsorbieron alrededor del 95\%; mientras que los otros alrededor del 90\%. Los mejores resultados se consiguieron con el CA AF30-60, con un rendimiento de $42 \%$, humedad $7,73 \%$ y cenizas $4,59 \%$. Estos resultados sugieren que se podría promover el cultivo intensivo de la calabaza y el aprovechamiento integral de esta Cucurbitaceae, ya que su cáscara es un buen precursor para la obtención de carbón activado con un alto nivel de adsorción y, por lo tanto, un carbón activado de buena calidad.
\end{abstract}

Palabras clave: adsorción, azul de metileno, tiempo de activación, agente activante, ácido fosfórico, cloruro de zinc

${ }^{1}$ Universidad Nacional Agraria La Molina (UNALM), Av. La Molina s/n, La Molina, Lima, Perú.

* Autor de Correspondencia: fharevalo@lamolina.edu.pe 
Calidad y rendimiento del carbón activado de

\begin{abstract}
Activated carbon (CA) was obtained from the peel of the pumpkin (Cucurbita ficifolia Bouchë) by chemical activation, using phosphoric acid $\left(\mathrm{H}_{3} \mathrm{PO}_{4}\right.$ at 30 and $\left.60 \%\right)$, and zinc chloride $\left(\mathrm{ZnCl}_{2}\right.$ at $1 \%)$, as activating agents. These three groups were undergone three different activation times (45, 60 and 75 minutes) to obtain nine treatments. Each treatment was repeated three times. The yield, humidity and ash of the nine treatments were found. In addition, the adsorption capacity of methylene blue was evaluated. The results indicate that the activating agent influences the adsorption capacity of the dye. The obtained activated carbons with phosphoric acid adsorbed approximately $95 \%$ of the methylene blue; while the other CA around $90 \%$. The best results were achieved with the CA AF30-60, with a yield of $42 \%$, humidity $7,73 \%$, and ash $4,59 \%$. These results suggest that the intensive cultivation of the pumpkin, and the integral use of this Cucurbitaceae could be promoted since its peel is a good precursor to obtain activated carbon with a high level of adsorption, and therefore, an activated carbon of good quality.
\end{abstract}

Key words: adsorption, methylene blue, activation time, activating agent, phosphoric acid, zinc chloride

\section{Introducción}

El carbón activado es una forma de carbón que se prepara en la industria, con el objeto de obtener un producto con un alto grado de porosidad y una elevada área superficial; de este modo adquiere una gran capacidad de adsorción para diversos compuestos, tales como colorantes, materiales orgánicos y metales pesados, entre otros (Alslaibi et al. 2013). El carbón activado se caracteriza porque, además de su extensa área superficial y elevada porosidad, presenta grupos funcionales en su superficie que le confieren reactividad superficial y carácter anfotérico (Alslaibi et al. 2013; Ioannidou y Zabaniotou 2007).

Para la elaboración de carbón activado, mayormente se utiliza cáscara de coco, bambú, madera y carbón animal. A estos materiales también se les llama precursores (Ioannidou y Zabaniotou 2007). Sin embargo, existen investigaciones que mencionan que los desechos agrícolas también se pueden usar para la elaboración de carbón activado, ya que su abundancia y su contenido de lignocelulosa favorece su elaboración; esto con la finalidad de disminuir los costos, evitar la depredación de recursos forestales y aprovechar de forma integral estos recursos (Alslaibi et al. 2013). En el Perú, se ha demostrado que a partir de los desechos agrícolas, se pueden obtener carbones activados (Degadillo 2011; Zamora 2010).
En general, el método para la obtención de carbón activado se basa en la activación del precursor. En palabras sencillas, consiste en la carbonización de un material carbonoso sometido a un reactivo. El reactivo utilizado se denomina agente activante; el tiempo que dura el proceso de carbonización y su temperatura reciben los nombres de tiempo de activación y temperatura de activación, respectivamente (Velázquez-Trujillo et al. 2010). Estos procesos generan un incremento de la porosidad del precursor que eleva el área superficial interna del carbón y le confiere una alta capacidad de adsorción. Se debe de tener en cuenta que el agente activante y su concentración, la temperatura de activación y el tiempo de activación, influyen significativamente en la capacidad de adsorción de un carbón activado (Alhamed 2006).

En el presente trabajo, se escogió como precursor a la cáscara del fruto maduro de la calabaza (Cucurbita ficifolia Bouchë), debido a su dureza y porque no se le da ningún uso a la misma. Por lo tanto, se podría promover el cultivo intensivo de la calabaza con el fin de ser utilizado integralmente, o la recolección de la cáscara, puesto que se puede almacenar por buen tiempo sin que se malogre. Finalmente, el objetivo de esta investigación es obtener carbón activado a partir de la cáscara del fruto maduro de la calabaza (Cucurbita ficifolia) y 
evaluar de qué manera los agentes activantes y los tiempos de activación influyen en la capacidad de adsorción del carbón activado obtenido, sobre el azul de metileno.

\section{Materiales y Métodos}

\section{Obtención de carbón activado}

\section{Preparación de la muestra}

Se adquirió $4 \mathrm{~kg}$ de calabaza (Cucurbita ficifolia) procedente de Huancayo - Junín. Se separó la cáscara y se cortó en trozos homogéneos de $10 \mathrm{~cm}^{2}$ aproximadamente; se limpió cuidadosamente y se secó en estufa a $60^{\circ} \mathrm{C}$ por 24 horas. Luego, fue molido hasta obtener partículas menores de un centímetro de diámetro (Diámetro $<1 \mathrm{~cm}$ ).

\section{Impregnación y activación}

Fue realizada con soluciones de ácido fosfórico y cloruro de zinc. Respecto al ácido fosfórico se emplearon soluciones al 30 y $60 \%$. La muestra molida fue impregnada en una proporción de $1_{\mathrm{g} \text { Muestra }}: 2_{\mathrm{g} \text { Reactivo }}$ por 16 horas y fue activada en una mufla marca Barnstead Thermolyn Modelo 1400 Furnace a $500^{\circ} \mathrm{C}$. En cuanto al cloruro de zinc, la muestra fue impregnada en una solución al $1 \%$ en una proporción de 1gMuestra: 1gReactivo por 24 horas y se activó en la misma mufla a $700^{\circ} \mathrm{C}$.

En ambos casos, se realizó la activación con tres distintos periodos de tiempo: 45, 60 y 75 minutos. En el Cuadro 1 se presenta el resumen del diseño experimental. Cada tratamiento tuvo tres repeticiones.

Los carbones activados (CA) obtenidos se lavaron con agua destilada hasta que el agua de lavado estuviera con un rango de $\mathrm{pH}$ entre 4 a 6. Se secó en estufa a $105^{\circ} \mathrm{C}$ y se molió hasta obtener un polvo fino, con un tamaño de partícula menor a $0,044 \mathrm{~mm}$. Esto último se logró con la ayuda de una malla Mesh 310.

\section{Evaluación del Carbón activado}

Rendimiento: Se pesó un crisol aparente y se le añadió $15 \mathrm{~g}$ de muestra. Se llevó a la mufla para su carbonización. Terminado el proceso se retiró de la mufla y se pesó nuevamente. Con esos valores, se calculó el rendimiento:

$$
\text { Rendimiento }(\%)=\frac{C-A}{B-A} \times 100
$$

Dónde:

A: peso del crisol (g).

B: peso del crisol con la muestra antes de ingresar a la mufla (g).

C: peso del crisol con la muestra después de salir a la mufla $(\mathrm{g})$.

Humedad: Según la norma ASTM D 1762 (ASTM 2013) se pesó un crisol vacío, luego se le añadió un gramo de CA y se volvió a pesar. Posteriormente, se colocó el crisol con CA sin

\begin{tabular}{lcc}
\hline Agente activante & Tiempo de activación (min) & Tratamientos \\
\hline \multirow{2}{*}{ Ácido fosfórico 30\% } & 45 & $\mathrm{AF} 30-45$ \\
& 60 & $\mathrm{AF} 30-60$ \\
& 75 & $\mathrm{AF} 30-75$ \\
\hline \multirow{2}{*}{ Ácido fosfórico 60\% } & 45 & $\mathrm{AF} 60-45$ \\
& 60 & $\mathrm{AF} 60-60$ \\
& 75 & $\mathrm{AF} 60-75$ \\
\hline \multirow{2}{*}{ Cloruro de zinc 1\% } & 45 & $\mathrm{ClZn} 1-45$ \\
& 60 & $\mathrm{ClZn} 1-60$ \\
& 75 & $\mathrm{Clzn} 1-75$ \\
\hline
\end{tabular}

Cuadro 1. Diseño del Experimento con calabaza (Cucurbita ficifolia). 
tapa en una estufa a $105^{\circ} \mathrm{C}$ por dos horas. Después, se guardó y colocó en un desecador por una hora para finalmente ser pesado. La humedad fue obtenida con la siguiente ecuación:

$$
\text { Humedad }(\%)=\frac{C-A}{B-A} \times 100
$$

Dónde:

A: peso del crisol (g).

B: peso del crisol con la muestra antes de ingresar a la mufla (g).

C: peso del crisol con la muestra después de salir a la mufla $(\mathrm{g})$.

Porcentaje de Cenizas: Según la norma ASTM D 1762 (ASTM 2013), a un crisol de peso conocido, se le añadió un gramo de CA y se pesó. Luego se colocó el crisol sin tapa en una mufla a $750^{\circ} \mathrm{C}$ por seis horas. Al finalizar, se colocó en un desecador por una hora. Por último, se pesó los crisoles. El porcentaje de ceniza fue calculado de acuerdo a la siguiente formula:

$$
\text { Ceniza }(\%)=\frac{C-A}{B-A} \times 100
$$

Dónde:

A: peso del crisol (g).

B: peso del crisol con la muestra antes de ingresar a la mufla (g).

C: peso del crisol con la muestra después de salir a la mufla $(\mathrm{g})$.

Adsorción de azul de metileno: Según la norma ASTM C 837 (ASTM 2014), se pesó 0,1 g de CA y se colocó en un tubo cónico de 50 ml. Se le añadió $50 \mathrm{ml}$ de azul de metileno al $1 \%$. Se homogenizo la muestra en un agitador magnético a una velocidad de $160 \mathrm{rpm}$ por 120 minutos. Cada 30 minutos, se tomó $5 \mathrm{ml}$ de muestra. Se filtró con papel Whatman \#42 y el filtrado se leyó en un espectrofotómetro marca Thermo Fisher Scientefic, Modelo Genesys 10S UV-Vis, a una longitud de onda de $660 \mathrm{~nm}$. Este proceso se realizó por un espacio de 120 minutos con intervalos de 30 minutos. Para este ensayo también se utilizó carbón activado comercial, de la marca Sigma, para poder comparar la capacidad de adsorción de los CA obtenidos, respecto a una versión comercial. Para determinar la adsorción del azul de metileno se utilizó la siguiente fórmula:

$$
\text { Adsorcion del azul de metileno (\%) }=\frac{A-B}{A} \times 100
$$

Dónde:

A: Absorbancia del patrón (muestra sin carbón activado).

B: Absorbancia de la muestra con el CA.

Análisis estadístico: Se realizó un ANOVA y una prueba de Tukey HSD con ayuda del programa STATHRAPHIC XV Centurion XV a los nueves tratamientos para hallar diferencias estadísticas.

\section{Resultados}

\section{Rendimiento}

En general, el CA obtenido con ácido fosfórico al $60 \%$ presenta el mayor rendimiento (ver Cuadro 2 y Figura 1). También se puede

\begin{tabular}{cccc}
\hline \multirow{2}{*}{ Agente activante } & \multicolumn{3}{c}{ Rendimientos por tiempos de activación (Minutos) } \\
\cline { 2 - 4 } & $\mathbf{4 5}$ & $\mathbf{6 0}$ & $\mathbf{7 5}$ \\
\hline Ácido fosfórico al 30\% & $36,58 \pm 3,12 \%$ & $42,13 \pm 2,31 \%$ & $33,75 \pm 4,10 \%$ \\
Ácido fosfórico al 60\% & $36,87 \pm 1,16 \%$ & $42,95 \pm 1,12 \%$ & $40,78 \pm 4,77 \%$ \\
Cloruro de zinc al 1\% & $23,50 \pm 4,51 \%$ & $30,13 \pm 0,17 \%$ & $30,15 \pm 3,04 \%$ \\
\hline : Desviación Estándar. & & &
\end{tabular}

Cuadro 2. Rendimiento de carbón activado de calabaza (Cucurbita ficifolia) a diferentes tiempos. 


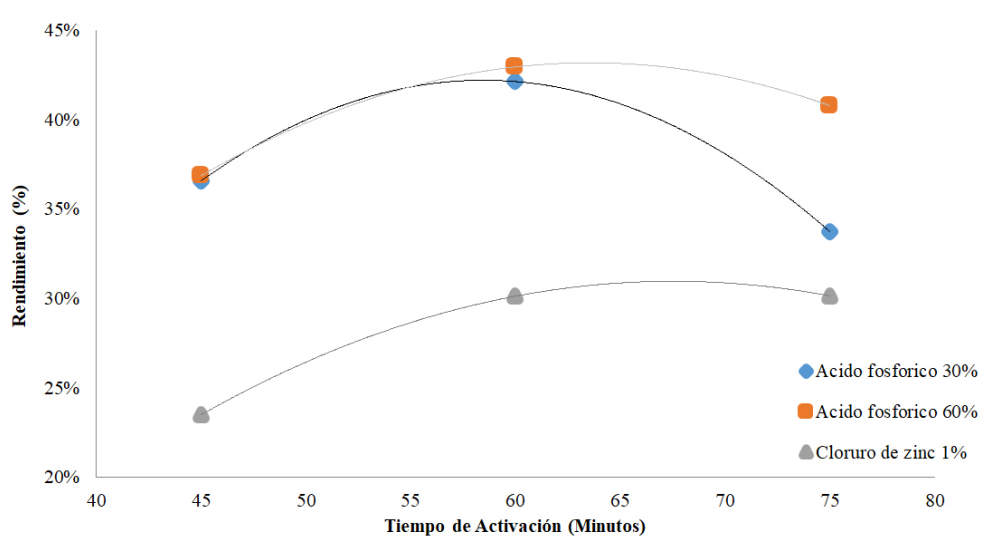

Figura 1. Rendimiento relacionado a los agentes activantes y los tiempos de activación.

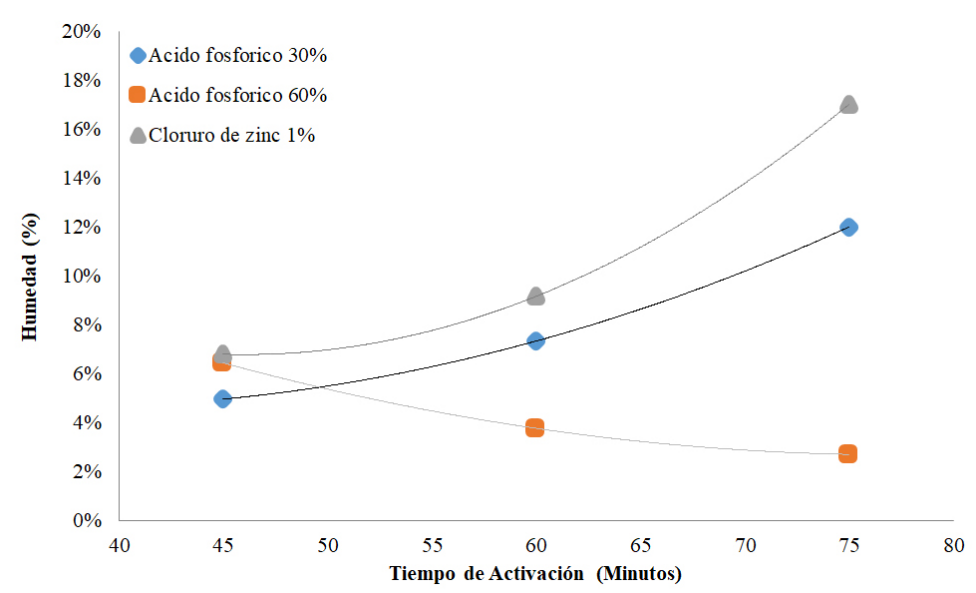

Figura 2. Porcentaje de humedad del carbón activado a diferentes tiempos.

observar que, el tiempo de activación más adecuado es de 60 minutos. Específicamente, el tratamiento AF60-60 presentó el mayor rendimiento con un valor de $42,95 \%$. En base a estos resultados, también se puede afirmar que, el agente activante influye en el rendimiento de CA.

\section{Humedad y Ceniza}

Se observa que el reactivo y el tiempo de activación influyen significativamente en el contenido de humedad de los CA obtenidos (ver Cuadro 3 y Figura 2). Es importante resaltar que los porcentajes de humedad en los CA obtenidos con ácido fosfórico al 30\% y cloruro de zinc al $1 \%$, tienen un comportamiento parecido, en donde se observa que el porcentaje de humedad es directamente proporcional al tiempo de activación; sin embargo, con el ácido fosfórico al $60 \%$, la relación es inversa.

Una variación significativa en el porcentaje de cenizas de los CA obtenidos, con ácido fosfórico, puede ser percibida en los tres tiempos de activación (ver Cuadro 3 y Figura 4); mientras que, en los valores de cenizas de los car- 


\begin{tabular}{cccc}
\hline \multirow{2}{*}{ Agente activante } & \multicolumn{3}{c}{$\%$ de humedad por tiempos de activación (Minutos) } \\
\cline { 2 - 4 } & $\mathbf{4 5}$ & $\mathbf{6 0}$ & $\mathbf{7 5}$ \\
\hline Ácido fosfórico al 30\% & $4,96 \pm 0,10 \%$ & $7,33 \pm 0,07 \%$ & $12,01 \pm 0,12 \%$ \\
Ácido fosfórico al 60\% & $6,44 \pm 0,13 \%$ & $3,76 \pm 0,15 \%$ & $2,69 \pm 0,18 \%$ \\
Cloruro de zinc al 1\% & $6,79 \pm 0,12 \%$ & $9,17 \pm 0,08 \%$ & $17,04 \pm 0,12 \%$ \\
\hline
\end{tabular}

土: Desviación Estándar.

Cuadro 3. Porcentaje de humedad de los carbones activados obtenidos.

\begin{tabular}{cccc}
\hline \multirow{2}{*}{ Agente activante } & \multicolumn{3}{c}{$\%$ de cenizas por tiempo de activación (Minutos) } \\
\cline { 2 - 4 } & $\mathbf{4 5}$ & $\mathbf{6 0}$ & $\mathbf{7 5}$ \\
\hline Ácido fosfórico al 30\% & $9,34 \pm 0,09 \%$ & $4,59 \pm 0,13 \%$ & $11,04 \pm 0,14 \%$ \\
Ácido fosfórico al 60\% & $6,37 \pm 0,08 \%$ & $10,56 \pm 0,15 \%$ & $8,75 \pm 0,11 \%$ \\
Cloruro de zinc al 1\% & $9,27 \pm 0,17 \%$ & $10,43 \pm 0,15 \%$ & $9,66 \pm 0,14 \%$ \\
\hline
\end{tabular}

土: Desviación Estándar.

Cuadro 4. Porcentaje de ceniza de los carbones activados obtenidos.

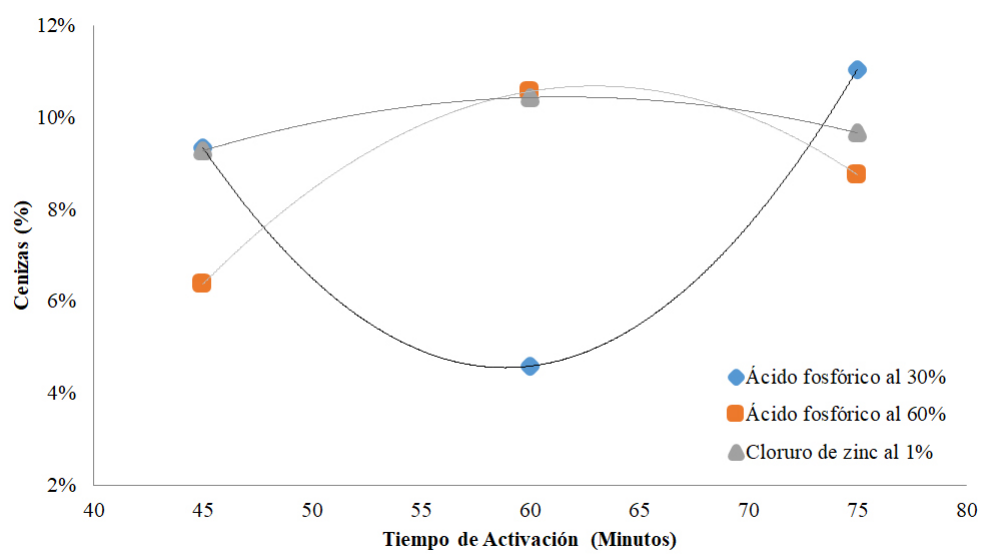

Figura 3. Porcentaje de ceniza de los carbones activados obtenidos.

bones activados obtenidos con cloruro de zinc, se observa que la variación es menor.

\section{Adsorción de azul de metileno}

Se aprecia que existen diferencias significativas entre agente activante y la capacidad de adsorción del CA obtenido; asimismo, no existen diferencias significativas entre el tiempo de activación de la materia prima y la adsorción del azul de metileno (ver Cuadro 5 y Figura 4).
En este ensayo, también es importante resaltar que, a partir del minuto 30 no se observa una variación significativa en el porcentaje de adsorción del azul de metileno.

Por otra parte, se observa que los CA obtenidos con ácido fosfórico presentan mayor capacidad de adsorción que los obtenidos con cloruro de zinc, incluso mayor que el carbón activado comercial. Asimismo, todos los CA con ácido fosfórico presentan valores superio- 


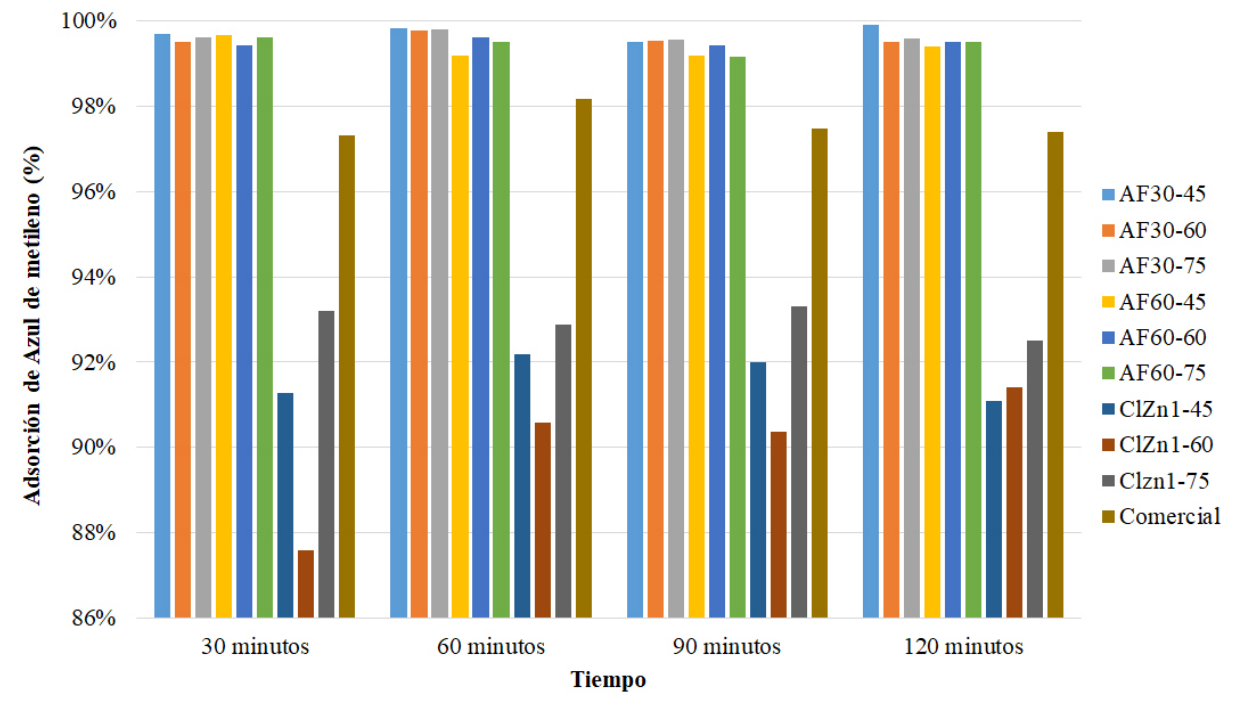

Figura 4. Porcentaje de adsorción de azul de metileno respecto al tiempo de adsorción.

res al 99\% de adsorción. Este resultado es prometedor si se considera que el CA de la versión comercial alcanzó un porcentaje del 96\%. Para finalizar este acápite, es importante destacar que el valor máximo de adsorción lo presentó el CA AF30-45.

\section{Discusión}

Los rendimientos de los CA obtenidos con ácido fosfórico y con tiempo de activación de 60 minutos son similares, es decir, que la tasa de impregnación utilizada para este experimento no es un factor significativo respecto al rendimiento como sí lo es el reactivo utilizado; esto confirma que el reactivo utilizado influye significativamente en el rendimiento (Degadillo 2011; Zamora 2010). Asimismo, se comparó los valores de rendimiento de los CA AF30-60 y AF60-60 cuyos rendimientos son $42,13 \%$ y $42,95 \%$, respectivamente. Es importante señalar que estos rendimientos son cercanos a los rendimientos del CA de pepas de níspero de palo, con un rendimiento de $45 \%$ (Degadillo 2011) y al de semillas de olivos, alrededor del 42\% (Baccar et al. 2009). Esto sugiere que la producción de CA a partir de la cáscara de calabaza podría reemplazar a algunos materia- les anteriormente mencionados. Por último, estos dos rendimientos son inferiores al del CA de cáscara de coco, el cual es 50\% (Gratuito et al. 2008). Aun así, resulta alentador, ya que la diferencia entre ambos es menor al 10\%.

Sobre lo observado en la humedad, se aprecia que a un mayor tiempo de activación, un mayor contenido de humedad en los CA con ácido fosfórico al $30 \%$ y cloruro de zinc. Esto implica que un mayor tiempo de activación genera un mayor número de poros en el CA, que al contacto con la humedad del ambiente, retiene un mayor número de moléculas de agua de la atmosfera; por lo tanto, aumenta el contenido de humedad (Degadillo 2011). Por otro lado, la humedad disminuye conforme aumenta el tiempo de activación en los CA con ácido fosfórico al $60 \%$, pues una mayor tasa de impregnación influye en la formación de grupos funcionales sobre la superficie del CA y esto afecta la capacidad de retención del agua (Moreno-Pirajan et al. 2007). Por lo tanto, en la Figura 2, se constata la influencia del tiempo de activación y la tasa de impregnación del ácido fosfórico sobre la humedad.

Haciendo un análisis integral a este estudio, se puede comenzar diciendo que las normas ASTM (2013) solo permiten CA con 


\begin{tabular}{|c|c|c|c|c|}
\hline \multirow{2}{*}{ Carbones activados obtenidos } & \multicolumn{4}{|c|}{$\begin{array}{c}\% \text { de adsorción respecto al tiempo } \\
\text { (Minutos) }\end{array}$} \\
\hline & 30 & 60 & 90 & 120 \\
\hline AF30-45 & $99,70 \pm 0,26 \%{ }^{\mathrm{a}}$ & $99,83 \pm 0,06 \%^{\mathrm{a}}$ & $99,50 \pm 0,26 \%{ }^{\mathrm{a}}$ & $99,90 \pm 0,21 \%{ }^{a}$ \\
\hline AF30-60 & $99,50 \pm 0,20 \% \%^{\mathrm{a}}$ & $99,77 \pm 0,06 \%^{\mathrm{a}}$ & $99,53 \pm 0,12 \%^{\mathrm{a}}$ & $99,50 \pm 0,15 \%{ }^{\mathrm{a}}$ \\
\hline AF30-75 & $99,63 \pm 0,25 \%{ }^{\mathrm{a}}$ & $99,80 \pm 0,00 \%{ }^{\mathrm{a}}$ & $99,57 \pm 0,15 \%^{\mathrm{a}}$ & $99,60 \pm 0,21 \%{ }^{a}$ \\
\hline AF60-45 & $99,67 \pm 0,25 \% \%^{a}$ & $99,20 \pm 0,44 \%^{\mathrm{a}}$ & $99,20 \pm 0,36 \%^{\mathrm{a}}$ & $99,40 \pm 0,12 \%{ }^{a}$ \\
\hline AF60-60 & $99,43 \pm 0,21 \%^{\mathrm{a}}$ & $99,63 \pm 0,15 \%^{\mathrm{a}}$ & $99,43 \pm 0,06 \%^{\mathrm{a}}$ & $99,50 \pm 0,10 \%{ }^{\mathrm{a}}$ \\
\hline AF60-75 & $99,63 \pm 0,23 \%^{\mathrm{a}}$ & $99,50 \pm 0,10 \%^{\mathrm{a}}$ & $99,17 \pm 0,35 \%^{\mathrm{a}}$ & $99,50 \pm 0,21 \%{ }^{a}$ \\
\hline CIZn1-45 & $91,27 \pm 2,15 \%^{\mathrm{b}}$ & $92,20 \pm 0,61 \%{ }^{b}$ & $92,00 \pm 1,04 \%{ }^{b}$ & $91,10 \pm 0.69 \% 0^{b}$ \\
\hline CIZn1-60 & $87,60 \pm 4,26 \%{ }^{\mathrm{b}}$ & $90,57 \pm 1,15 \%{ }^{b}$ & $90,37 \pm 1,47 \%^{\mathrm{b}}$ & $91,40 \pm 4,05 \%{ }^{\mathrm{b}}$ \\
\hline Clzn1-75 & $93,20 \pm 0,75 \%{ }^{\mathrm{b}}$ & $92,87 \pm 0,45 \%{ }^{\mathrm{b}}$ & $93,30 \pm 0,20 \%{ }^{\mathrm{b}}$ & $92,50 \pm 3,72 \%^{\mathrm{b}}$ \\
\hline Comercial & $97,33 \pm 0,12 \%^{\mathrm{a}}$ & $98,17 \pm 0,29 \%{ }^{\mathrm{c}}$ & $97,47 \pm 1,07 \%{ }^{\mathrm{c}}$ & $97,40 \pm 0,69 \% \%^{a}$ \\
\hline
\end{tabular}

Cuadro 5. Porcentaje de adsorción de azul de metileno respecto al tiempo.

una humedad inferior al 15\% y otras fuentes recomiendan seleccionar un CA con baja humedad, ya que su presencia disminuye la capacidad de adsorción (Valdivieso 2012). Dicho esto, en esta investigación, se seleccionaría a los CA AF60-60 y AF60-75, por presentar menor humedad, cuyos valores son 3,76 y $2,69 \%$ respectivamente. Por otro lado, comparado con la humedad del CA proveniente de cáscara de coco, cuyo rango es de 3 a 5\% (Zamora 2010), se diría que el primero está dentro del rango especificado y el segundo presenta una humedad menor; en consecuencia, se podría decir que poseen una capacidad de adsorción similar o mayor que el CA obtenido de cáscara de coco.

Respecto al contenido de cenizas, se ha reportado que a mayor contenido de esta, la capacidad de adsorción del CA suele disminuir; por lo tanto, se recomienda usar CA con bajo contenido de cenizas (Gratuito et al. 2008) y, en este caso, correspondería al CA AF30-60, cuyo valor es 4,59\% de cenizas. Otra elección adecuada podría ser el CA AF60-45, por presentar un valor de $6,37 \%$. Es importante tener en cuenta que estos valores son bajos si se comparan con el contenido de ceniza de los CA de pepas de nísperos (Degadillo 2011) y de bambú (Solís-Fuente et al. 2012), cuyos valores son 10,2 y $7,0 \%$, respectivamente; sin embargo, si se compara con el CA obtenido de cáscara de coco, resulta ser ligeramente superior, ya que dicho CA registra un valor de alrededor del $3,0 \%$. A pesar de ello, los resultados del contenido de cenizas de estos dos CA son indicadores de buena calidad, debido a que su contenido de cenizas es inferior al $15 \%$ (Degadillo 2011).

Analizando los resultados de adsorción de azul de metileno, no hubo ninguna variación después del minuto 30, como se mencionó antes; es decir que 30 minutos bastó para remover el $99 \%$ del colorante. En este punto, se recomendaría realizar estudios de cinética de adsorción para hallar menores tiempos. Por otra parte, se puede señalar que, las capacidades de adsorción de los CA con ácido fosfórico son similares, estadísticamente hablando, lo que pone de manifiesto que, el tiempo de activación y la tasa de impregnación, por lo menos en este estudio, no son factores significativos, como sí lo es el agente activante. Esto 
coincide con lo reportado por Solís-Fuente et al. (2012) quienes concluyeron que el agente activante influye significativamente en la remoción de la coloración de jugo de caña.

Haciendo un análisis a los agentes activantes, se sabe que el uso de ácido fosfórico ocasiona que los CA posean un $\mathrm{pH}$ acido; mientras que el uso de cloruro de zinc ocasiona un $\mathrm{pH}$ menos ácido y, este hecho, afecta la capacidad de adsorción de los CA obtenidos (Moreno-Pirajan et al. 2007). Así pues, los CA menos ácidos o ligeramente básicos, tenderán a adsorber compuestos ácidos, como el azul de metileno, debido a la atracción de cargas opuestas; no obstante, los CA obtenidos con ácido fosfórico presentan un mayor porcentaje de adsorción que los CA obtenidos con cloruro de zinc (Moreno-Pirajan et al. 2007). Respecto a esta observación, se especula que los CA obtenidos con ácido fosfórico presentan una mayor cantidad de mesoporos que los CA obtenidos con cloruro de zinc, por lo que la adsorción del azul de metileno se debería principalmente a los mesoporos más que al pH (Zamora 2010; Solís-Fuente et al. 2012).

Por otra parte, se sabe que la adsorción de azul de metileno es un indicador de la capacidad de adsorción de moléculas de gran tamaño que permite determinar si el carbón activado obtenido es adecuado para la eliminación de contaminantes orgánicos y colorantes; en consecuencia, para un tiempo de adsorción de 30 minutos, se puede afirmar que todos los CA obtenidos a partir de la cáscara de calabaza, a excepción del tratamiento ClZn1-60, son adecuado para este uso, debido a su capacidad de adsorción superior al 90\% para el azul de metileno (Tan et al. 2008).

\section{Conclusiones}

Los resultados de este estudio demuestran que se puede obtener CA con ácido fosfórico al 30 y $60 \%$ y cloruro de zinc al $1 \%$ a partir de la cáscara del fruto maduro de la calabaza (Cucurbita ficifolia). El mejor carbón activado se obtuvo con ácido fosfórico al 30\% y con un tiempo de activación de 60 minutos (AF3060 ); debido a que presenta una buena capaci- dad de adsorción de azul de metileno y cumple los requisitos de cenizas y humedad de la ASTM.

Los carbones activados obtenidos con ácido fosfórico al 30 y al $60 \%$ y con tiempo de activación de 60 minutos (AF30-60 y AF60-60) presentan los mayores rendimientos, que son 42,13 y $42,95 \%$ respectivamente. Para un tiempo de adsorción de 30 minutos, todos los CA obtenidos a partir de la cáscara de calabaza, a excepción del tratamiento ClZn1-60, tienen una capacidad de adsorción superior al 90 por ciento para el azul de metileno.

En el presente estudio, todos los CA obtenidos a partir de la cáscara de calabaza, tratados con ácido fosfórico, sea al 30 o al 60\%, tienen una capacidad de adsorción del azul de metileno, mayor que la del carbón activado comercial utilizado en este ensayo.

\section{Agradecimientos}

Se agradece al Dr. Enrique Gonzáles del Laboratorio de Maderas y al Laboratorio Tabusso de la Universidad Nacional Agraria La Molina por su apoyo y facilidades otorgadas para la finalización de este proyecto de investigación.

\section{Bibliografía}

Alhamed, A. 2006. Activated carbon from dates' stone by $\mathrm{ZnCl}_{2}$ activation. Journal Engineering and Science 17(2):75-98.

Alslaibi, T; Abustan, I; Ahmad, M; Foul, A. 2013. Review: comparison of agricultural by-products activated carbon production methods using surface area response. Journal of Chemical Technology and Biotechnology 88:1183-1190. DOI: https://doi.org/10.1002/ jctb.4028

ASTM (American Society for Testing and Materials). 2013. Standard Test Method for Chemical Analysis of Wood Charcoal. ASTM D176284. 2013. West Conshohocken, EEUU. 2 p.

ASTM (American Society for Testing and Materials). 2014. Standard Test Method for 
Methylene Blue Index of Clay. ASTMC837-09. 2014. West Conshohocken, EEUU. 3 p.

Baccar, R; Bouzid, J; Feki, M; Montiel, A. 2009. Preparation of activated carbon from Tunisian olive-waste cakes and its application for adsorption of heavy metal ions. Journal of Hazardous Materials 162(2-3):1522-1529. DOI: https://doi.org/10.1016/j.jhazmat.2008.06.041

Degadillo, G. 2011. Obtención de carbones activados a partir de pepas de níspero de palo (Mespilus communi) y su aplicación para la adsorción de fenoles. Tesis Mg. Sc. Lima, Perú, Pontificia Universidad Católica del Perú. 118 p.

Gratuito, MK; Panyathanmaporn, T; Chumnanklang, RA; Sirinuntawittaya, N; Dutta, A. 2008. A Production of activated carbon from coconut shell: optimization using response surface methodology. Journal of Bioresource technology 99(11):4887-4895. DOI: https:// doi.org/10.1016/j.biortech.2007.09.042

Ioannidou, O: Zabaniotou, A. 2007. Agricultural Residues as Precursors for Activated Carbon Production A Review. Renewable \& Sustainable Energy Reviews 11(9): 1966-2005. DOI: https://doi.org/10.1016/j.rser.2006.03.013

Moreno-Piraján, JC; Navarrete, LF; Giraldo, L; García, V. 2007. Adsorción de Fenol y 3-Cloro Fenol sobre Carbones Activados mediante Calorimetría de Inmersión. Revista de Información tecnológica 18(3):7180. DOI: https://dx.doi.org/10.4067/S0718$\underline{07642007000300009}$

Solís-Fuentes, J; Morales-Téllez, M; Ayala-Tirado, R; Durán-de-Bazúa, M. 2012. Obtención de carbón activado a partir de residuos agroindustriales y su evaluación en la remoción de color del jugo de caña. Revista de Tecnología, Ciencia, Educación 27(1):36-48.

Tan, IA; Ahmad, AL; Hameed, BH. 2008. Adsorption of basic dye on high-surface-area activated carbon prepared from coconut husk: Equilibrium, kinetic and thermodynamic studies. Journal of Hazardous Materials 154(13):337-346.

Valdivieso, C. 2012. Obtención de carbón activado por método físico a partir de la semilla de aguaje (Mauritia flexuosa) procedente de la región Loreto. Tesis Lic. Lima, Perú, UNALM. $87 \mathrm{p}$.

Velázquez-Trujillo, A; Bolaños-Reynoso, E; Pliego-Bravo, YS. 2010. Optimización de la producción de carbón activado a partir de bambú. Revista Mexicana de Ingeniería Química 9(3):359-366.

Zamora, G. 2010. Obtención de carbón activado a partir de semillas de dos palmeras de la amazonia peruana shabaja (Attalca phaleratal) y aguaje (Mauritia flexiosa). Tesis Lic. Lima, Perú, UNALM. 88 p. 